\title{
1. Introduction: regulatory governance in developing countries
}

\section{Martin Minogue and Ledivina Cariño}

This book examines the problems involved in analysing and assessing the regulatory reforms that are now on the economic reform agenda in many developing countries. In developed economies, such well-established reforms are generally regarded as belonging to the post-privatisation phase; but in developing economies, privatisation has itself been an incomplete and faltering process, so that associated regulatory reforms are either new, or poorly understood and conceived: often, privatisation and regulatory reforms will proceed piecemeal, without proper sequencing or coordination. Despite the assumption by influential aid donors such as the World Bank that such reforms will have the merit of taking bureaucrats out of business, many factors in developing country political and economic systems demonstrate a propensity for regulation inside government. Since poor governance is regarded by aid donors as a major obstacle to effective economic reforms, a concern with institutionalising regulatory governance is a crucial aspect of the regulatory reform agenda, and indeed of broader programmes of governance and public sector reforms.

A significant feature of the contemporary research agenda on competition and regulation in developing economies has therefore been the emphasis placed on the institutions and processes of governance surrounding and conditioning the progress of these economic policy reforms. This does no more than reflect one of the leading themes in the developed country literature on regulation, usually labelled as 'regulatory governance' and deploying a new concept of the 'regulatory state' to set against the more conventional categories of 'welfare' or 'provider' state. This corresponded clearly enough to the 'new public management' model of public action, which rested on a similar counterposition of the traditional state and the 'enabling' state. The thrust of recent work in this field has been to emphasise the significance of 'regulatory governance' as an essential context that may determine the prospects for regulatory policy success or failure, and to remind policy reformers that their proposals are not introduced into a contextless environment. 


\section{INTERPRETING REGULATORY GOVERNANCE}

First, we need to recall what regulatory governance is, how it has emerged as a significant element in the literature and practice of regulation in developed countries, and what purchase it has in the rather different economic and political conditions of developing countries. It is possible to suggest at least tentative answers to these questions (tentative because many of the conceptual issues are 'contested' and because for developing country systems empirical research in this area remains sparse and patchy).

A starting point is to acknowledge that regulatory governance is now fully accepted as a significant part of the literature on regulation in general and on privatisation and post-privatisation regulatory reforms in particular. The traditional literature always had a strong institutional component focusing on the role of legal institutions and practices, in an approach which saw regulation as primarily rule-based and principally involving issues of compliance and accountability (Ogus, 2002). But the most recent literature on developed, and particularly European, countries has been dominated by analysts such as Majone, intent on expanding the range of analysis to include the interactions of legal and administrative systems with political institutions and processes (Majone, 1996, 1997); by political scientists such as Moran (2001, 2002), concerned to establish broader concepts of 'the regulatory state', 'regulatory capture' and 'regulatory space' as a way of bringing together the political and economic issues inherent in contemporary state-market debates; and Wilks (1996), who demonstrates the diversity of regulatory ideas and practice even within an ostensibly uniform European system. An important dimension emerged in formulations of self-regulation, resting on relations of trust, as a means of escaping from more formalistic regulatory overload and inadequate forms of political accountability (Ayres and Braithwaite, 1992). In the first place, then, the analysis of regulation must go beyond examination of the formal rules that govern relationships between the public and private sectors, to the broader framework of state-market relations, and drawing on disciplinary contributions that range across economics, law, politics, and public policy and management.

Correspondingly, since regulation can be categorised as a distinctive mode of policymaking, or of governance (Majone, 1999), it must be examined in relation to the general public policy process. Majone's focus is on the extensive delegation of policymaking powers to what he describes as non-majoritarian institutions, by which he means the various new regulatory bodies but also judiciaries, tribunals and other regulatory and adjudicative agencies intrinsic to the public sector. His concern is that these institutions may become dangerously independent of the political process 
and so lack accountability. On the other hand Majone locates this development in a political logic which demands of politicians that they 'achieve credible policy commitments' (Majone, 1999, p. 4). An important issue raised here is that 'democratically accountable principals can transfer policy making powers to non-majoritarian institutions, but they cannot transfer their own legitimacy', which may be a significant agency cost where in theory 'delegation is justified only if its benefits exceed agency costs' (Majone, 1999, p. 7). Perhaps, therefore, a key insight is that 'independence from political control does not mean independence from public accountability' (p. 11). Majone concludes that in designing an effective regulatory state the key variables are:

1. the extent to which decisions are delegated to an independent agent rather than taken by the political principal;

2. the nature of the structure of governance itself, particularly in determining the agent's degree of independence from the political process;

3. the rules that specify the procedural framework, e.g. reason-giving requirements, consultative processes;

4. the scope for political principals to overrule agency decisions;

5. the relative autonomy of financial resources;

6. the extent of ex post monitoring, e.g. legislative oversight, judicial review, citizen's complaints procedure.

What is striking here is the way Majone moves between the narrower conception of regulatory instruments and procedures, and the broader conception of politics in ways that underwrite the usefulness of the label 'regulatory governance'. This means looking behind the institutional façade to grasp the 'real world' of public action. The orthodox model, with its emphasis on legal rules, formal structures of organisation, rational policy choice and the assumed implementation of formal policies has serious limitations. It oversimplifies the complex processes from which policy debates and decisions emerge; and neglects the political discourse of rule-making and rule application, notably the interplay of ideas, interests and resources, and the ways in which these interactions determine outcomes. It therefore fails to explain either policy and organisational failures, or policy innovations and successes, and obscures both the significance of relations of power and influence, and the extent to which public policies and their results are determined by conflicts and bargains between conflicting stakeholders, whether internal or external to public bureaucracies.

Analysis based on process may be conducted in ways that focus on real decision scenarios; the factors that determine choice between policy options; the actions that define implementation outcomes, and deficits; 
and the relations between key actors. Such analysis helps to identify stakeholder interests and networks, and to explain both failed and effective policy changes, in particular by identifying winners and losers; and assists more realistic and feasible policy design, which in turn should produce more predictable and effective policy outcomes. This analytical model can be applied to any field of policy, and therefore has obvious value as a tool for improving and evaluating regulatory policies, and asking the significant questions about the effectiveness of regulatory policies in achieving broader systemic objectives such as poverty reduction.

In sum, analysis of regulation involves analysis of ideas, institutions, processes, activities and actors, in all their myriad interrelationships in economic, social and political spheres. The conceptions of the regulatory state and regulatory space offer us the broadest possible analytical framework in direct contradiction to the narrow formulations favoured in the standard literature on regulation, so capably criticised by Black (2002) for its preoccupation with the correction of market failure, when wider issues of the management of a risk society, and the achievement of social justice, should be equally insistent concerns.

\section{INTERPRETING POLICY TRANSFER}

When we turn to the application of this analysis to regulatory reforms in developing countries, the contributions to this book demonstrate that problems can be identified associated with the strong tendency to transfer to developing countries 'best practice' models of regulation rooted in the different economic, social and political conditions of developed countries. These contributions focus first of all on conceptual issues and debates. Phillips, in Chapter 2, challenges the contention that the regulatory state model is a useful framework within which to develop an understanding of the evolution of the state in different parts of the world. Her argument is set out in three dimensions. First, empirically, a variety of differing states are simply slotted into the preconceived model rooted in industrial state systems and processes, but 'the regulatory state model has generally yielded little purchase on the processes of state transformation and the nature of contemporary states in the huge variety of institutional and national settings outside the "core" of the advanced industrialised economies' (p. 18). Second, analytical approaches are constrained by a preference for the construction of ideal types of the state in a globalising economy, with a consequently reductivist allocation of specific cases to one or other of these idealised models. Third, a highly functionalist account of the regulatory state obscures our understanding of the complex institutional and political 
landscapes characteristic of developing states, and the extent to which differing forms of governance exist alongside regulatory governance in most contexts. Her main conclusion is that these landscapes are "characterised more by "regulation without a regulatory state" than with the sorts of institutional and strategic structures stipulated by the regulatory state model' (p. 35); and that while empirical reforms are being widely pursued and constructed, the institutional and political conditions for success are found in only very limited cases: 'the regulatory state model can often prove more of a hindrance than a help in the study of regulation, at least in the developing world' (p. 36).

Phillips concedes that much existing reform activity in developing countries is based on an ideal type of regulatory state, and that some of the relevant institutional reforms are taking place. Majone (Chapter 3), is interested in what he terms 'spontaneous regulatory convergence' (p. 41), created by the demands for legal, institutional and economic harmonisation emerging from global institutions and agreements. Much of the drive towards international regulatory convergence operates through the setting of uniform international standards, particularly in areas of science and the regulation of risk. Majone quotes a World Bank study which demonstrates that stringent rules designed to protect health in EU countries would seriously damage African export trade, and argues that it is in the interests of developing countries to ensure that they are able to participate in and shape adjustments of international policies and rules. While calling for attention to 'regulatory science' and procedural rationality in decision-making, he emphasises that this has significant political as well as technical implications, since regulatory independence and efficiency must be achieved within a framework of political and public accountability.

Discussing 'policy imitation' in these contexts, Majone suggests that models emanating from economically and politically powerful countries are most likely to be emulated, and that this process may demonstrate 'push and pull' tendencies. These are themes explored by Minogue (Chapter 4). This chapter draws attention to conceptual difficulties involved in analysis of regulatory governance reforms in developing countries. These difficulties relate to contested definitions of regulation, to the weakness of comparative frameworks of analysis, to poor data and information about the real impact of core governance reforms, and to disagreements about what constitutes the proper scope of regulation. Crucially, an idealised model rooted in developed country practice and aid donor preferences is transplanted with little attempt to modify it to fit the many and varied political and institutional contexts in a range of developing and transitional economies. Minogue argues that the core ideal of 'independent regulation' rests on a naive view of the political process and a misunderstanding of political 
priorities, which in developing country contexts often mean that economic governance cannot be insulated from overriding political considerations: 'aid donors . . . must learn to accept that local political cultures will shape and mediate externally-derived economic and managerial reforms, rather than being transformed by them' (p. 78).

This message is partly challenged by Vass, in Chapter 5. He suggests that, with due modification and adaptation, the UK model of regulatory governance can appropriately be emulated elsewhere, the prize to be gained being improved economic efficiency and more effective provision of public goods and services. Yet his survey of recent developments in regulatory reforms in the UK demonstrates how necessary it is to locate analysis of such reforms within the institutional and policy framework in which they are being formulated and applied. In the UK system, as Vass emphasises, this means giving considerable weight to the legal and constitutional settings that determine the forms and effectiveness of public accountability mechanisms. Doubtless the achievement of sound mechanisms of accountability is desirable in developing country governance too, but where these are deficient or weak, legal-constitutional models will have little real purchase until broader governance and public management reforms are introduced. But such reforms are open to similar objections of cultural inappropriateness and contested values.

\section{INSTITUTIONAL REFORMS, CAPACITY AND CAPTURE}

Specific cases of regulatory reform in developing countries illustrate some significant issues. Elsewhere Ogus has described the necessary legal institutions and structures that provide the essential foundation for effective regulatory practice (Ogus, 2002) and has identified the institutional and behavioural weaknesses in developing country legal systems that make regulatory reforms difficult to achieve (Ogus, 2004). Here, in Chapter 6, Ogus and Zhang use empirical evidence, largely from China, to argue the merits of deregulation where regulatory regimes seem to be serving other than regulatory purposes. Their discussion of licensing systems demonstrates that such systems at best are overelaborate and dysfunctional, and at worst are kept in place to support rent-seeking activities by political and bureaucratic elites. The reduction and streamlining of such processes would, it is argued, remove constraints damaging to enterprises and economic growth in developing countries. While this reverts to the conventional argument for deregulation, it is worth noting that such reforms will come up hard against the very logic they identify as causal to the problem in the first place: political 
and bureaucratic self-interest, and political values that favour governmental control of a wide range of economic activities and agencies.

Legaspi's study (Chapter 7) of regulation in the context of local economic development in two contrasting Philippine cities echoes some of the discussion in Ogus and Zhang. What is demonstrated here is that issues of regulation and competition frameworks are not to be confined to central government contexts, but are significant at decentralised levels of governance, where 'local government is placed at a focal point of relationships and linkages with the private sector' (p. 138). Legaspi argues that regulation of local businesses and economic activity is part of the 'social regulation' function of local governments acting in the public interest. But her cases reveal dysfunctions associated with over-regulation on the one hand, and related opportunistic corruption on the other. Regulation may then work in the private rather than the public interest. This situation is exacerbated by confused lines of authority and responsibility between national and local regulators, and a lack of appropriate resources and capacity for effective regulation at the local level. In short, regulation at local levels of governance is desirable, but too often flawed, and rarely 'independent'.

As guardians of the public interest, regulators should in principle have both technical capacity and independence. Most developing countries started with a single regulator for multiple sectors, given the original focus on economic regulation and the relatively simple technologies of the regulated industries. It was expected that a single body could guide the provision of such disparate services as power, water, communications and transportation. With rapid technical changes, the norm for regulators now is to specialise in one industry even as they tackle multiple goals of economic and social regulation, as well as the regulation of competition.

Regulators must (again, in principle) be abreast of the technological sophistication of the regulated industry, and have working knowledge of its needs. This would allow them to assess the capacity of firms to deliver required services, to evaluate their petitions for rate increases and to balance these against the demands of consumers and clients. Their lawyers and accountants must match the industry's own staff so that neither the state nor the public are misled by the arguments and figures produced by the regulated firms. In developing states, such technical capacity is scarce and is often best developed within the regulated industries themselves. Taking advantage of this, some regulated firms provide the equipment and training for their regulators or contrive the appointment of industry insiders as regulators (see Coronel, 1998, for examples of this in the Philippine telecommunications industry). Eldridge and Goulden (Chapter 14) emphasise that an important response to these problems of building 
organisational and managerial autonomy reside within regulatory agencies themselves. They elaborate a diagnostic model that, if sensitively applied and adapted to individual agency conditions, would, they argue, substantially improve the ability of agency staffs to identify their own capacity constraints, build their internal institutional capacity, and strengthen their performance and effectiveness as regulators, a necessary (though not sufficient) step towards genuine regulatory independence.

The 'independence' of a regulatory agency should mean relative insulation from both political and industry pressures. This may be aimed for through constitutional measures, judicial review arrangements, location outside the normal state bureaucratic system, or incentives to regulatory staff. Recognition by the state of the importance of such forms of insulation is essential. Representation of and consultation with different interests forestalls capture by any single one. Nevertheless, representation is not without problems: as shown in Brown and Woodhouse (Chapter 11) in their study of water management and regulation in a rural region in South Africa, representation of black communities did not ensure awareness by these communities of the issues and their own interests. They suggest that proxies like advocacy non-governmental organisations (NGOs) may voice black interests better, but acknowledge that these may also filter the needs of black communities through a particular lens. Meanwhile, commercial interests complain that their higher ability to pay is not rewarded with stronger representation in the regulatory system.

The importance of regulators to the state is shown in both their hierarchical position and their functions. Hierarchical placement may seem like a simple concept. The higher they are placed in the bureaucracy, the less regulators are subject to administrative checks. Independent commissions have more autonomy than those attached to cabinet departments or those placed lower in the hierarchy. But agency placement may be highly complex, as Müller and Uys show in their study of water services in South Africa (Chapter 10). The national level sets standards and provides the regulatory framework. This is largely the function of the Ministry of Water Affairs, but it has to work in conjunction with the Ministry of Finance relative to water tariffs, and it is 'the executive political office bearer' of the Department of Water Affairs and Forestry that acts as the overall regulator of water services. This picture is complicated by concurrent national and provincial functional areas, exclusive provincial areas, and local government functional areas all of which have offices assigned to each function. The allocation of domestic service provision to local government bodies seems to accord with the best principles of decentralised public services, but in practice runs into the same problems of local capacity and capture identified in Legaspi (Chapter 7). The lesson here seems to be that 
institutional reforms will not be worth the legislative paper they are written on unless supported by real changes in political attitudes, managerial practices and organisational competencies.

The importance given by the state to regulators is also shown by the functions it entrusts to them. However, having multiple functions does not necessarily strengthen regulation, as two Philippine cases demonstrate. Basilio (Chapter 8) depicts the problems of saddling the Philippines Ports Authority (PPA) with developmental and revenue-raising functions. As a result, the PPA has developed a partnership with the shipping, cargo handling and terminal operators it is supposed to regulate and has encouraged them to form a virtual monopoly. Because it shares in their income, the PPA has also allowed them to make excessive increases in their customers' fees. This study also warns that while it might seem appropriate for government officials to be tasked with obligations to protect the public interest, where the institutional conditions for regulatory independence are absent, this overlooks the weakness that government may itself be a party motivated by self-interest. In the case of the PPA, government's desire for revenues seemed to override the goals of efficiency and competitiveness.

A similar situation is described by Cuaresma in Chapter 12 in respect of regulation of water services, where the government regulatory office, being funded by the private concessionaires, is unable to control them. Both cases also show that capture may be so entrenched in the surrounding legislative and contractual arrangements that the regulators are either part of the system of capture, or are powerless to resist it. Capture may be written into the law and be beyond the regulator's power to prevent. Basilio (Chapter 8) shows pitfalls in the law governing the PPA, which is then used by a president to promulgate an Executive Order practically requiring the board to do away with competition.

Moreover, the promulgators of a regulation do not have to be privateregarding to write rules that can be justified more by private than by public interest. This is the lesson of Ogus and Zhang's study of licensing procedures in developing countries (Chapter 6). They compared licensing integrated in the set-up process (SL) and those independent of it (IL), finding SL regimes imposing more entry costs but not necessarily improving compliance, saving compliance costs or saving monitoring costs for officials. Instead, benefits may accrue more to the bureaucrats giving the licence, agencies responsible for subsequent checking procedures, existing suppliers and politicians. Some of the benefits will take place through resort to corruption.

These examples show that regulatory capture is not simply the ability of regulated firms to get regulators to decide regularly in their favour. It should also encompass the view that government is an interested party. 
Moreover, laws and regulations, even those seemingly neutral, need to be analysed for their potential ability to tilt decisions in favour of private interests. Representation and participation, as means to ward off such capture, also need to be examined for their efficacy in giving voice to these previously excluded and to the general public. This is a reminder of the deeply political nature of regulatory policymaking in developing countries.

\section{REGULATION, MARKETS AND POVERTY}

A core objective of development policy, both for leaderships in developing countries, and for the aid agencies that are the principal funders and drivers of economic reforms, is to reduce poverty, in line with the Millennium Development Goals. It is no simple matter to trace the linkages between the overarching poverty reduction strategy, and specific economic reforms of the kind represented by market-oriented policies that promote privatisation, competition and regulation. The dominant philosophy is still rooted in the classical view that economic growth will, through an inevitable process of 'trickle down' of benefits, inexorably reduce poverty. But the process remains stubbornly opaque, and resistant to easy generalisation. Even if it is accepted that economic growth can, and has, lifted millions of people out of some officially designated level of poverty in many developing countries over the past three decades (notably in China), some vexed and contentious issues remain. One of these is inequality of distribution of the benefits of economic growth, not merely in terms of income, but in terms of what the poor are able to command in other equally significant ways. One such area is the degree to which the poor are able to ensure access to core resources such as water, energy, and transport and communications. Under the traditional 'development' or 'provider' state model, access for the poor to basic needs was protected by the public interest role defined for the state (and supported by aid agencies). But the shift to an 'enabling' state has switched the emphasis to market-driven provision of services. The question that arises, and is yet to be fully answered, is whether this will be beneficial or damaging to poor groups and communities.

Some cases explored in the last part of this book sketch, if not the answers to this question, at least the outlines of what must be examined in order to answer it. In the case of telecommunications, Alampay (Chapter 9) uses Amartya Sen's well known perspective on the ability of people to command 'substantive freedoms' to live the lives they choose, or their 'capabilities', to examine the significance of universal access to information and communication technologies (ICTs) for this kind of capability. This analysis is based on an empirical study in the large Philippine city of Puerto 
Princesa. Alampay concludes that while new technologies provide new possibilities for government to improve the capabilities of poorer groups, it is evident that traditional socioeconomic and cultural barriers continue to impede these advances in communication and information, so that already privileged groups gain most of the associated benefits. Capabilities, in Sen's terms, are easily enough identified, but not so easily acquired by those with few resources, in the absence of protection from regulatory bodies tasked with social as well as technical objectives.

The discontinuity between the narrower economic and technical objectives of market-based competition and regulatory reforms and the broader social objectives that tend to be the province of state-centred policies emerges clearly from the case studies here of the water sector (three related to South Africa, one to the Philippines). In South Africa, substantive institutional reforms have been introduced by a government motivated by the pressing basic needs of large parts of its population and the strength of its own political commitment to meet these needs. Müller and Uys (Chapter 10) set the scene with a useful account of these institutional (and legislative-based) changes. They describe a complex array of instruments and agencies, with potential for a 'multitude of regulatory institutions' and related duplications, confusions and conflicts. Privatisation does not appear to be an issue in itself: 'the predominant issue in South Africa is less who delivers the service than at what price' (p. 222). While a political debate takes place broadly between proponents of marketisation or at least full cost recovery, and those who argue for the need to 'decommodify' what is a public good, the devil appears to be in the policy detail, with many uncertainties about how the reformed institutional structures will work in practice, or how competition for access to this scarce resource by different user groups will be played out.

These issues are illuminated by the account by Brown and Woodhouse (Chapter 11), based on research into the implementation of key provisions in the National Water Act of 1998, to realise the efficient management of water resources while also redressing past inequities in accessibility to water. Set in the Inkomati Water Management Area (one of 19 such areas in South Africa) their research focuses on the introduction of a catchment management agency system intended to integrate different demands for water use, and the related groups of water users. A major lesson is that in seeking to correct historical disadvantages in water use and access, decentralising and participatory strategies may well be less appropriate than firm and centralised political direction, and mediation between contesting groups. At the same time, central agencies seem to have limited capacity to intervene effectively at local and regional levels. Unsurprisingly, then, the protection and strengthening of weak stakeholders (such as black farmers, 
poor domestic users) intended by the national reforms has not yet been achieved. Brown and Woodhouse urge attention to improved participatory mechanisms based on appropriate alliances of 'weak' stakeholders, combined with pragmatic attention to the needs of commercial users through flexible incentive systems, so offering a 'third way' that avoids the more stark choices between 'commodification' or 'decommodification' models of water provision.

The problems that attend privatisation of water provision in the absence of strong regulatory safeguards are classically illustrated in Cuaresma's study of the operation of two private water concessions in Metro Manila, the Philippines (Chapter 12). Conceived as a response to service failures by government-owned water corporations, the concessionaire agreements establish no obligation on concessionaires to provide water services to the approximately 1.3 million poor Manila residents without access to piped water: blighted and poor communities are last in priority for water connection, but first to experience reduced water supply or reduced water pressure in times of water scarcity. Meanwhile prices have risen by 500 per cent since 1997, without any corresponding commitments on service targets to poor areas. Cuaresma identifies a range of regulatory deficits and makes sensible recommendations to repair these. But the inbuilt flaws in the concession agreements, and the political influence of the powerful local elites who dominate the concession consortia, suggest that the prospect for such reforms is realistically bleak. A general lesson seems to be that privatisation into a weak regulatory framework may attract private investment, but will not improve provision of water to the poor.

A leading issue is not just the supply of water, and its price, but also how safe drinking water is. Again, it is usually poor communities who are left with unsafe water, at tremendous cost in terms of health. Mackintosh and Uys, in Chapter 13, set out the public policy response to this issue in South Africa, where in the 1990s up to 18 million people were without adequate water supply and some 25 per cent of deaths in the one to five age group could be attributed to poor water and sanitation. The policy response was to put in place a 'water services ladder' that populations could climb progressively. This has brought substantial improvements in supply, with ten million people brought onto the first rung of the ladder in terms of a basic level of supply. But drinking water quality remains a concern, particularly in rural areas. Despite appropriate legislative rules, compliance by water services authorities (mainly local municipalities) is often low, with poor understanding of the legislation, of regulatory requirements, and an absence of appropriate financial and managerial resources and skills to service these requirements. Mackintosh and Uys demonstrate through rural case studies that major contamination problems can rapidly be identified and corrected 
through adherence to the existing national quality management programme, which aims to increase compliance with national standards; they also show the benefits of cooperative governance initiatives between provincial and local levels in the context of this regulatory setting, something germane to the situation analysed in Brown and Woodhouse (Chapter 11).

In the final chapter (14) Eldridge and Goulden address the problem of inadequate capacities in regulatory agencies. Starting from the assumption that good regulation depends on the effective and efficient management of people and processes within regulatory agencies, they construct a diagnostic model that can be used by agencies to identify their own capacity needs and may be used then to establish means to improve regulatory performance. Testing and modifying this model on the basis of research in ten telecommunications regulatory agencies in Southern Africa, they offer it as a helpful tool for regulatory agencies generally. They are careful (and surely right) to present this as a design based on 'good practice', with due attention to be paid, in any agency seeking effective reforms, not merely to the technical content of whatever is being regulated, but to systemic issues of administrative and political context, internal and more general organisational cultures, and to the appropriateness (or otherwise) of inserting into these significant governance contexts practices imported from external sources or based on external experiences. This considered and intelligent design of regulation in local contexts is the prize to be gained from a proper attention to, and understanding of, the broad principles of regulatory governance.

\section{REFERENCES}

Ayres, I. and J. Braithwaite (1992), Responsive Regulation: Transcending the Regulation Debate, Oxford: Oxford University Press.

Black, J. (2002), Critical Reflections on Regulation (Discussion Paper No. 4), London: Centre for Analysis of Risk and Regulation, London School of Economics and Political Science.

Coronel, S. (1998), Pork and Other Perks: Corruption and Governance in the Philippines, Manila: Philippine Centre for Investigative Journalism.

Majone, G. (1996), Regulating Europe, London: Routledge.

Majone, G. (1997), 'From the positive to the regulatory state: Causes and consequences of the changes in modes of governance', Journal of Public Policy, 17(2), 139-67.

Majone, G. (1999), 'The regulatory state and its legitimacy problems', West European Politics, 22(1), 1-24.

Moran, M. (2001), 'Not steering but drowning: Policy catastrophe and the regulatory state', The Political Quarterly, 72(4), 414-27.

Moran, M. (2002), 'Understanding the regulatory state', British Journal of Political Science, 32, 391-413. 
Ogus, A. (2002), 'Regulatory institutions and structures', Annals of Public and Cooperative Economics, 73(4), 627-48.

Ogus, A. (2004), 'The importance of legal infrastructure for regulation (and deregulation) in developing countries', Working Paper No. 66, CRC, University of Manchester, Manchester.

Wilks, S. (1996), 'Regulatory compliance and capitalist diversity in Europe', Journal of European Public Policy, 3, 536-59. 